\title{
Metode Simple Additive Weighting dalam Sistem Pendukung Keputusan Pemilihan Karyawan Berprestasi (Studi Kasus : PT. Indomarco Prismatama cabang Tangerang 1)
}

\author{
Syahriani Syam ${ }^{1)}$ Mahmud Rabidin ${ }^{2)}$ \\ Jurusan Teknik Informatika, Fakultas Teknik, Universitas Islam Syekh Yusuf, Jl. Mulana Yusuf No.10 Tangerang \\ Banten 15118, Indonesia (10pt normal italic) \\ 1) ssyam@unis.ac.id \\ 2) todaymahmud93@gmail.com
}

\begin{abstract}
Abstrak. Warehouse (gudang) PT. Indomarco Prismatama cabang Tangerang 1 melakukan pemilihan karyawan berprestasi untuk memacu semangat karyawan dalam meningkatkan dedikasi dan kinerjanya. Metode Simple Additive Weighting (SAW) adalah salah satu metode yang digunakan dalam proses pengambilan suatu keputusan. Konsep dasar metode SAW adalah mencari penjumlahan terbobot dari rating kinerja pada setiap alternatif pada semua atribut. Metode SAW membutuhkan proses normalisasi matriks keputusan $(X)$ ke suatu skala yang dapat diperbandingkan dengan semua rating alternatif yang ada. Salah satu penerapan metode Simple Additive Weighting $(S A W)$ adalah pemilihan karyawan berprestasi. Tujuan dari penelitian ini adalah memilih karyawan berprestasi di PT. Indomarco Prismatama cabang Tangerang 1. Hasil dari penelitian ini menunjukkan bahwa metode SAW tepat untuk memilih karyawan berprestasi karena dapat memperoleh karyawan yang berkualitas sesuai dengan harapan perusahaan maupun pimpinan.
\end{abstract}

Kata kunci: Simple Additive Weighting, rating, karyawan, berprestasi.

\begin{abstract}
Warehouse PT. Indomarco Prismatama Tangerang branch 1 conducts employee selection to encourage employee enthusiasm in improving their dedication and performance. Simple Additive Weighting $(S A W)$ method is one method used in the decision making process. The basic concept of the SAW method is to find the weighted sum of performance ratings on each alternative on all attributes. The SAW method requires the process of normalizing the decision matrix $(X)$ to a scale comparable to all existing alternative ratings. One application of the Simple Additive Weighting (SAW) method is the selection of outstanding employees. The purpose of this study is to choose outstanding employees at PT. Indomarco Prismatama branch of Tangerang 1. The results of this study indicate that SAW method is appropriate to select employee achievement because it can obtain qualified employees in accordance with company expectations and leadership.
\end{abstract}

Keywords: Simple additive weighted, rating, Employee, achievement

\section{Pendahuluan}

Penggunaan teknologi pada era ini sangat memberikan dampak yang luar biasa bagi kehidupan manusia. Hal tersebut menjadikan teknologi sebagai sarana membantu menyelesaikan permasalahan permasalahan di berbagai bidang. Dalam praktek kehidupan sehari - hari. Persoalan karyawan seringkali menjadi krusial yang terkadang memicu perbedaan pendapat dalam pemilihan karyawan berprestasi. Pengelolaan sumber daya manusia dari suatu perusahaan sangat mempengaruhi banyak aspek penentu keberhasilan kerja dari perusahaan tersebut.

Warehouse (gudang) PT. Indomarco Prismatama cabang Tangerang 1 melakukan pemilihan karyawan berprestasi untuk memacu semangat karyawan dalam meningkatkan dedikasi dan kinerjanya. Pemilihan karyawan berprestasi dilakukan secara periodik akan tetapi belum optimal. dalam pelaksanaannya pemilihan karyawan berprestasi masih mengacu pada absensi dan nilai proforma atau jumlah nilai rupiah barang hilang yang dibebankan oleh karyawan saja.

Metode Simple Additive Weighting (SAW) adalah salah satu metode dalam proses pengambilan keputusan.metode ini memiliki kemampuan penilaian yang lebih tepat dan akurat, karena berdasarkan pada nilai kriteria dan bobot yang ditentukan, sehingga membantu menyelesaikan masalah pemilihan karyawan berprestasi dengan cepat dan tepat.

\section{Rumusan Masalah}

Berdasarkan latar belakang masalah yang telah diuraikan, maka rumusan masalah yang didapat yaitu : "Apakah metode Simple Additive Weighting (SAW) dapat diterapan dalam sistem pendukung keputusan 
untuk pemilihan Karyawan Berprestasi Pada PT. Indomarco Prismatama cabang Tangerang 1?”

\section{Batasan Masalah}

Berdasarkan latar belakang di atas agar pembahasan dalam penelitian ini lebih fokus, maka penulis mencoba merancang aplikasi dengan menerapkan metode Simple Additive Weighting (SAW) pada sistem pendukung keputusan pemilihan karyawan berprestasi pada PT. Indomarco Prismatama Cabang Tangerang. Dalam pembuatannya, penulis menggunakan Bahasa pemprograman PHP dan Database MySQL.

\section{Tujuan Penelitian}

Adapun tujuan dari penelitian ini adalah merancang aplikasi sistem pendukung keputusan pemilihan karyawan berprestasi pada PT. Indomarco Prismatama Cabang Tangerang menggunakan metode Simple Additive Weighting (SAW) .

\section{Manfaat Hasil Penelitian}

Adapun manfaat dari penelitian ini adalah sebagai berikut :

\section{Manfaat Teoritis}

Hasil dari penelitian ini diharapkan dapat memberikan suatu kontribusi dalam bidang keilmuan teknologi informasi yang berkaitan dengan sistem pendukung keputusan khususnya dalam penggunaan metode Simple Additive Weighting (SAW).

\section{Manfaat Praktis}

Hasil dari penelitian ini dapat dijadikan masukan untuk perusahaan agar dapat meningkatkan kinerja karyawan di PT. Indomarco Prismatama cabang Tangerang 1.

\section{Bahan dan Metode:}

\section{Simple Additive Weighting (SAW)}

Metode Simple Additive Weighting (SAW) sering juga dikenal dengan penjumlahan terbobot. Konsep dasar metode Simple Additive Weighting disarankan untuk menyelesaikan masalah penyeleksian dalam sistem pengambilan keputusan multiproses.

Konsep dasar metode SAW adalah mencari penjumlahan terbobot dari rating kinerja pada setiap alternatif pada semua atribut. Metode SAW membutuhkan proses normalisasi matriks keputusan (X) ke suatu skala yang dapat diperbandingkan dengan semua rating alternatif yang ada (Rizkandari dan Saptono, 2016).

\section{Sistem Pendukung Keputusan}

Sistem pendukung keputusan adalah sistem berbasis komputer interaktif yang membantu pengguna dalam penilaian dan pemilihan. Sistem tidak hanya menyediakan penyimpanan dan pengambilan data tapi juga meningkatkan akses informasi tradisional dengan dukungan untuk pembuatan model pengambilan keputusan dan penalaran berbasis model (Dian dan Permana, 2015).

Hal perlu ditekankan disini adalah bahwa SPK bukanlah suatu tool pengambil keputusan, melainkan sebagai tool pendukung (Permatasari, 2015). Sistem ini digunakan untuk membantu pengambilan keputusan dalam situasi yang semiterstruktur dan situasi yang tidak terstruktur, dimana tak seorang pun tahu secara pasti bagaimana keputusan seharusannya dibuat (Muslim dan Baihaqi, 2016)

\section{Karyawan}

Karyawan adalah manusia yang mempunyai sifat kemanusiaan, perasaan dan kebutuhan yang beraneka ragam. Kebutuhan ini bersifat fisik maupun non fisik yang harus dipenuhi agar dapat hidup secara layak dan manusiawi. Hal ini menyebabkan timbulnya suatu pendekatan yang berdasarkan pada kesejahteraan karyawan dalam manajemen personalia (Ashari, 2015)

\section{Prestasi Kerja}

Prestasi kerja adalah suatu hasil kerja yang dicapai seseorang dalam melaksanakan tugas-tugas yang dibebankan kepadanya yang didasarkan kecakapan, pengalaman dan kesungguhan serta waktu (Januari, 2015).

\section{PHP}

PHP (PHP Hypertext Preprocessor) adalah sebuah bahasa interpreter yang memiliki kemiripan dengan bahasa $\mathrm{C}$ dan Perl, mempunyai kesederhanaan dalam perintah dan digunakan untuk pembuatan aplikasi web (Fitriyani, 2017).

\section{Metode}

\section{Metode Penelitian}

Metode yang digunakan dalam penelitian ini adalah metode kuantitatif. Dalam mendapatkan data yang lebih akurat dan detail, maka objek yang akan diteliti dengan melakukan pengumpulan data di PT. Indomarco Prismatama cabang Tangerang 1.

\section{Sampel}

Sampel dalam penelitian ini, peneliti hanya memilih bagian administrasi, warehouse (gudang), retur supplier dan toko, receiving, Perishable, dan issuing. Jumlah karyawan pada 6 bagian tersebut ada 150 karyawan. Penarikan sampel pada penelitian ini secara acak, kemudian ukuran sampel (Sample Size) minimal ditentukan berdasarkan Rumus Slovin:

Dimana:

$$
n=\frac{N}{N \cdot d^{2}+1}
$$

$\mathrm{n}=$ Ukuran sampel

$\mathrm{N}=$ Ukuran populasi

$\mathrm{d}=$ Tingkat kesalahan penarikan sample yang diinginkan

Tingkat kesalahan penarikan sample yang diinginkan dalam penelitian ini ditentukan sebesar $10 \%$, maka banyaknya ukuran sample adalah sebesar

$$
\begin{aligned}
n & =\frac{N}{N \cdot d^{2}+1} \\
n & =\frac{150}{150 \cdot(0.1)^{2}+1} \\
& =60
\end{aligned}
$$




\section{Metode Pengumpulan Data}

Metode pengumpulan data dalam penelitian ini berupa data sekunder, Berupa data yang diperoleh secara tidak langsung, misalnya dari dokumentasi, dan informasi lainnya yang relevan.Jenis data yang digunakan dalam penelitian ini adalah data sekunder yang di peroleh dari perusahaan PT. Indomarco Prismatama cabang Tangerang 1.

\section{Instrumentasi}

Penelitian ini dilakukan dengan menggunakan data sekunder yaitu data - data dan nilai kriteria dari masing - masing karyawan. Kriteria yang sudah ditentukan akan di jadikan acuan guna memperoleh data dalam pemilihan karyawan yang berprestasi.

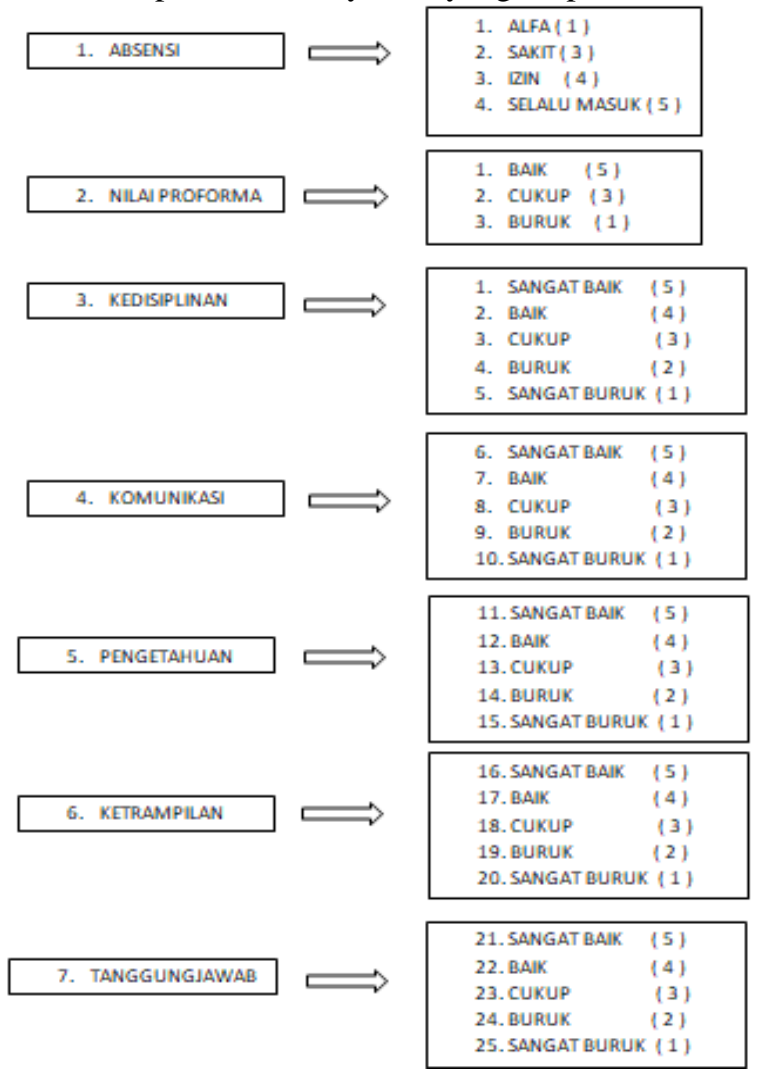

Gambar 1. Instrumen Nilai Kriteria

\section{Teknik Pengujian}

Pada Penelitian ini, teknik pengujian yang digunakan dengan black box yaitu bentuk pengujian yang tujuannya untuk menunjukkan fungsi cara kerja perangkat lunak, apakah antara input dan output dapat berjalan sesuai yang diharapkan atau tidak.

\section{Hasil dan Pembahasan}

1. Use Case Diagram yang Sistem Usulan Berdasarkan Gambar 2 Use Case Diagram yang diusulkan terdapat:

- Satu sistem yang mencakup seluruh kegiatan.

- Dua aktor yang melakukan kegiatan, yaitu staff dan manager.

- Dua belas use case yang dilakukan oleh aktor.

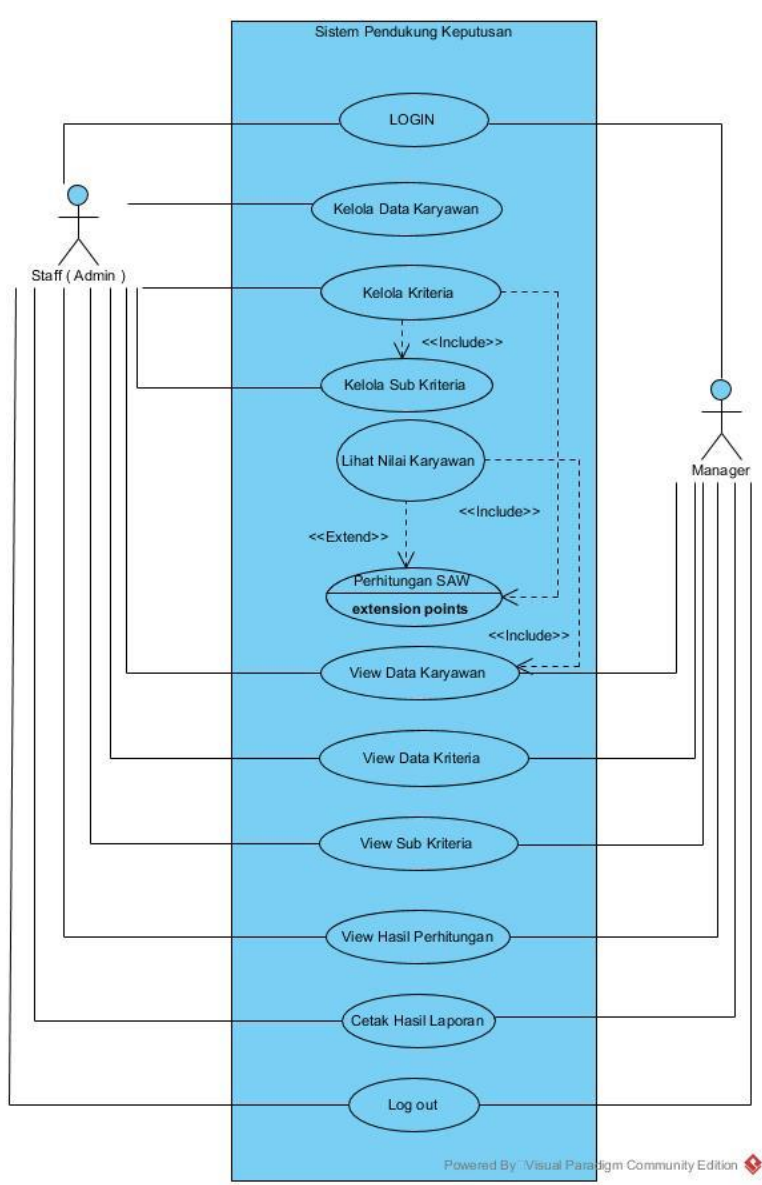

Gambar 2. Use Case Diagram yang diusulkan

2. Mockup Program

a. Mockup Halaman Login

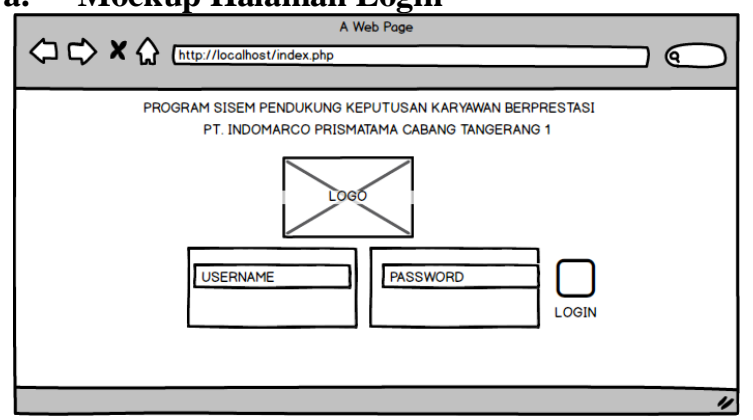

Gambar 3. Mockup Halaman Login

b. Mockup Halaman Utama (Home )

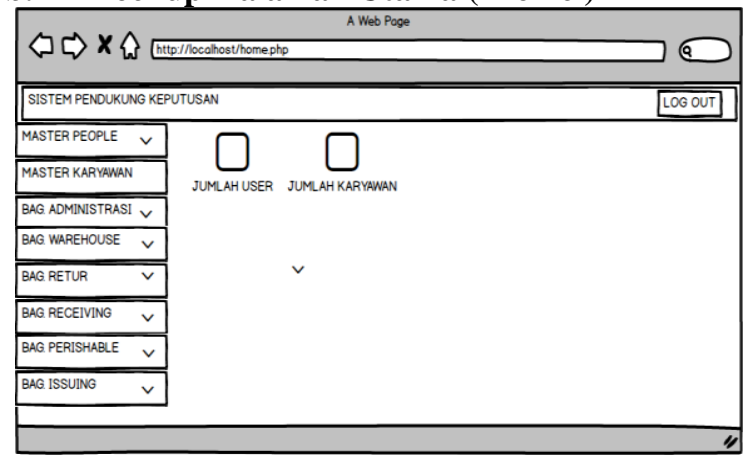

Gambar 4. Mockup Halaman Utama ( Home ) 


\section{c. Mockup Halaman Tambah Karyawan}

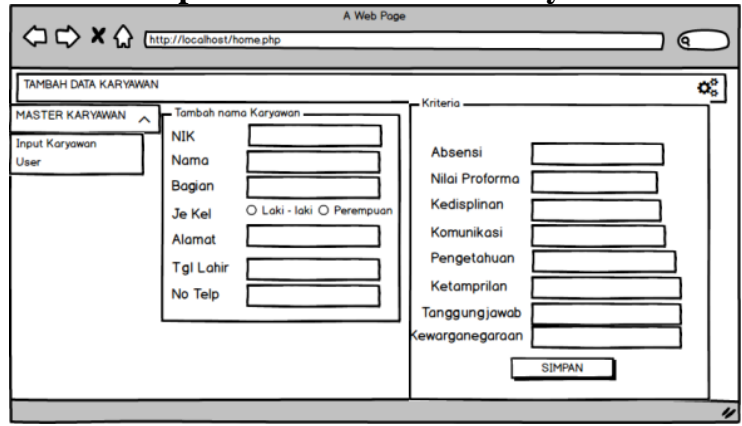

Gambar 5. Mockup Halaman Tambah Karyawan

\section{Tampilan Program}

a. Tampilan login pada aplikasi

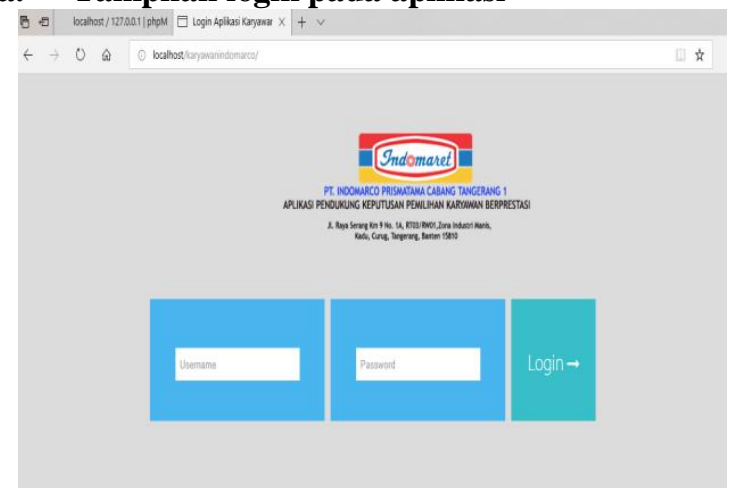

Gambar 6. Tampilan Login

b. Tampilan Menu Utama pada aplikasi

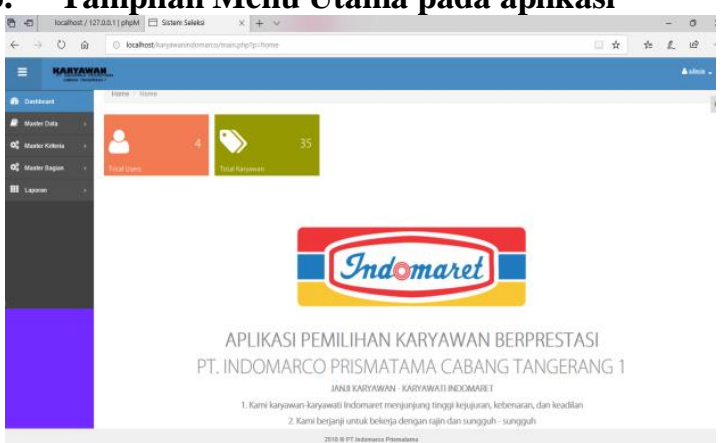

Gambar 7. Tampilan Menu Utama

\section{c. Tampilan form isi data karyawan}

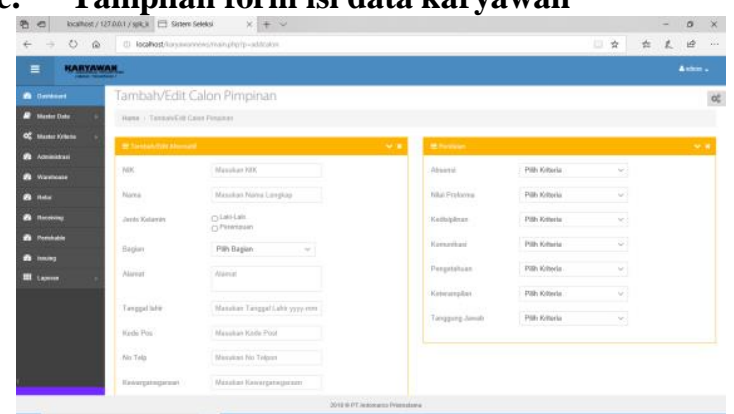

Gambar 8. Form isi data karyawan

\section{Testing}

Black Box Testing
Berikut ini merupakan tabel pengujian mengunakan Black Box Testing, sebagai berikut:

Tabel 1 Black Box Testing

\begin{tabular}{|c|c|c|c|c|c|}
\hline Na. & 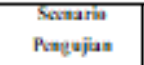 & Toul Gase & $\begin{array}{l}\text { Panilyante } \\
\text { Diharaphan }\end{array}$ & Pasil Parqujan & States \\
\hline T. & 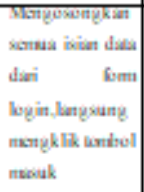 & $8=$ & 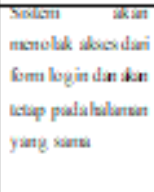 & $\begin{array}{c}\text { 플 } \\
i=-\end{array}$ & Vyant \\
\hline 2 & 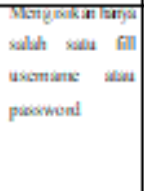 & 플 & 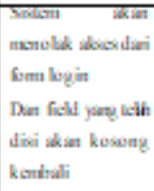 & 플 & Vyant \\
\hline 3. & 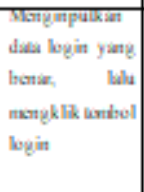 & $\overline{=}$ & 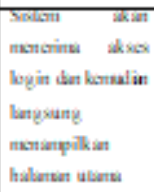 & & Vantr \\
\hline 7 & 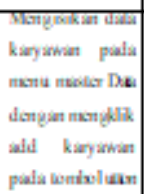 & $\overline{5}$ & 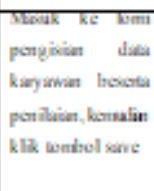 & 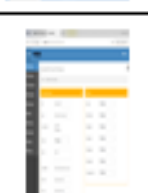 & Tant \\
\hline
\end{tabular}

\section{Kesimpulan}

Berdasarkan hasil analisa dan perumusan masalah yang telah di teliti dan dilakukan, maka penulis menyimpulkan bahwa dengan adanya aplikasi sistem pendukung keputusan pemilihan karyawan berprestasi dengan metode Simple Additive Weighting (SAW) dapat membantu manager dalam memilih karyawan yang berprestasi karena prosesnya lebih cepat dan mudah.

\section{Saran}

Beberapa hal untuk menanggulangi permasalahan agar dapat mencapai hasil yang lebih baik lagi, maka penulis mengemukakan saran dan pendapat yaitu:

1. Sistem memiliki massa, sehingga harus melakukan pemeliharaan dan pengawasan terhadap sistem tersebut agar dapat berfungsi dengan baik.

2. Dalam penginputan data - data karyawan, sistem ini masih manual, sehingga dapat dikembnagkan yaitu data - data karyawan tersebut dapat di upload agar lebih memudahkan admin

3. Sistem ini masih belum dihubungkan dengan aplikasi absensi pada perusahaan, sehingga nanti dalam pengembangannya sistem ini akan terhubung dengan sistem absensi yang sudah ada.

\section{Daftar Pustaka}


Jurnal Keilmuan dan Aplikasi Teknik

UNISTEK, 2019, Vol. 6, No.1

Ashari. (2015). Penerapan Fuzzy Multiple Criteria Decision Making ( MCDM ). 1, 14-19.

Dian, S. \& Permana, H. (2015). Kejuruan Teknik Komputer Dan Jaringan Yang Terfavorit Dengan Menggunakan Multi-Criteria Decision Making, 2, 11-19.

Fitriyani, M. R. (2017). Sistem Pendukung Keputusan untuk Kenaikan Jabatan Aparatur Sipil Negara Struktural pada Badan Pengelola Keuangan dan Aset Daerah (BPKAD) Kabupaten Lampung Tengah dengan Metode Simple Additive Weighting.Januari, C. I. (2015). PRESTASI KERJA ( Studi pada Karyawan PT . Telekomunikasi Indonesia , Tbk Wilayah Malang). Adm. Bisnis, 24, 1-8.

Muslim, H. \& Baihaqi, M. A. M. (2016). Sistem Pendukung Keputusan Untuk Pemilihan Hotel Dengan Simple Additive Weighting (SAW) Berbasis Web. Semin. Nas. Teknol. Inf. dan Multimed, 6-7

Permatasari, S., Kridalaksana, H.H., \& Suyatno, A. (2015). Sistem Pendukung Keputusan Pemilihan Program Studi di Universitas Mulawarman Menggunakan Metode Tsukamoto (Studi kasus: Fakultas MIPA). $J$. Inform, 10.

Rizkandari, A., S., Saptono, R. \& , W. (2016) Pemanfaatan Metode Simple Additive Weighting (SAW) Dalam Penentuan Mahasiswa Berprestasi Tingkat Universitas Sebelas Maret Surakarta. J. Teknol. Inf. ITSmart, 3(34). 